\title{
Steady state nutrition by transpiration controlled nutrient supply
}

\author{
W. G. BRAAKHEKKE and D. A. LABE ${ }^{1}$ \\ Department of Soil Science and Plant Nutrition, Wageningen Agricultural University, P.O. Box 8005, \\ 6700 EC Wageningen, The Netherlands. ${ }^{1}$ Present address: Institute for Agricultural Research, Ahmadu \\ Bello University, P.M.B. 1044, Zaria, Nigeria
}

Key words: nitrogen nutrition, nitrogen productivity, Pennisetum americanum (L.) Leeke, programmed nutrient addition, relative growth rate, steady state nutrition, transpiration coefficient, transpiration controlled nutrient supply

\begin{abstract}
Programmed nutrient addition with a constant relative addition rate has been advocated as a suitable research technique for inducing steady state nutrition in exponentially growing plants. Transpiration controlled nutrient supply is proposed as an alternative technique for plants with a short or no exponential growth phase. A two-weeks experiment with transpiration controlled nitrogen supply to Pennisetum americanum was carried out to evaluate this method.

After an adaptation phase a constant plant $\mathrm{N}$-concentration was maintained, while the relative growth rate decreased rapidly. The transpiration coefficient was almost constant in time and insensitive to moderate $\mathrm{N}$-stress, but increased sharply when plant $\mathrm{N}$-concentration dropped below $1760 \mathrm{mmol} / \mathrm{kg}$ DW. Relative growth rate and nitrogen productivity showed a steep decline at the lowest $\mathrm{N}$ concentrations (about $1000 \mathrm{mmol} / \mathrm{kg} \mathrm{DW}$ ). Nitrogen productivity was optimal at about $1760 \mathrm{mmol} / \mathrm{kg}$ DW.

The results show that transpiration controlled nutrient supply is applicable in research and gives accurate results in growth analysis. When the transpiration coefficient is known, the nutrient solution can be adjusted to give any desired plant $\mathrm{N}$-concentration, except for the lowest concentrations.
\end{abstract}

\section{Introduction}

In studying physiological and morphological responses of plants to nutrient supply, it is essential to be able to grow plants with a well-defined, constant, suboptimal nutrient status. This condition, referred to as steady state nutrition (SSN), is usually characterized by a constant internal concentration of the growth limiting nutrient. It can be achieved by supplying nutrients at a rate proportional to the actual growth rate of the plant. For plants that grow exponentially, Programmed Nutrient Addition (PNA) with a constant relative addition rate (RAR; see the appendix) has proven to be a suitable technique (Ingestad and Lund, 1986).
In experiments that outlast the exponential growth phase PNA with constant RAR fails to maintain SSN. When, for some internal or external cause (like a change in biomass allocation or self shading), the potential relative growth rate of a plant decreases, a constant RAR will result in a gradually improving nutrient status, eventually leading to luxurious consumption and elimination of the nutritional control of growth.

To maintain SSN, the nutrient supply should be adjusted to the changing potential growth rate. One can think of several ways to achieve this. RAR could be made a function of time, plant size or development stage. The rate of nutrient addition could also be controlled by the actual growth rate of the plant as calculated by 
simultaneous computer simulation (Van Koninckxloo, 1986; Schapendonk et al., 1990). Both approaches require detailed information on the growth and nutrient demand of the plant.

In this paper we present an alternative approach, which requires little information on plant growth. We use the transpiration rate of the plant to control the supply of the limiting nutrient. The transpiration coefficient (TC) has been found to be rather constant in time and independent of nutrient status in many situations, provided the nutrient level is not 'too low' (Van Keulen and Seligman, 1987; De Wit, 1958). If this holds, transpiration controlled nutrient supply results in a situation where the limiting nutrient is supplied at a rate that is proportional to the actual growth rate:

$$
\mathrm{d}(\mathrm{ANPL}) / \mathrm{dt}=0.001 \cdot \mathrm{d}(\mathrm{DWPL}) / \mathrm{dt} \cdot \mathrm{CN} \cdot \mathrm{TC}
$$

(abbreviations are listed in the appendix).

The plants are grown in an initial solution that contains all essential nutrients except the limiting nutrient to be studied. This nutrient is supplied by daily compensating for the transpiration with a complete nutrient solution. Different levels of nutrient stress are induced by varying the concentration of this nutrient solution $(\mathrm{CN})$. The overall plant $\mathrm{N}$-concentration (NCPL) approaches $\mathrm{CN} \cdot \mathrm{TC}$ after a short adaptation phase:

$$
\mathrm{NCPL} \rightarrow 1000 \cdot \mathrm{d}(\text { ANPL }) / \mathrm{d}(\mathrm{DWPL})=\mathrm{CN} \cdot \mathrm{TC}
$$

Here we present the results of an experiment with transpiration controlled nitrogen supply to Pearl millet (Pennisetum americanum (L.) Leeke), using a communicating vessel system designed to allow frequent measurement of transpiration and non-destructive observation of several plant characteristics. The aim was to evaluate the proposed method of maintaining steady state nutrition and to test its applicability in a study on the influence of internal nitrogen status and age of the plant on its transpiration coefficient, relative growth rate and nitrogen productivity.

\section{Materials and methods}

\section{Plant material}

Seeds of pearl millet Pennisetum americanum (L.)Leeke (= P. typhoides S. \& H.) were germinated in moist quartz sand without additional nutrients. Five days after sowing (DAS) the seedlings were transplanted to a container with a complete nutrient solution with $5.2 \mathrm{~m} M$ nitrogen. At the start of the experiment (12 DAS) 12 plants were selected for equal size and used for the experiment.

\section{The communicating vessel system}

The plants were mounted in glass cylinders $(4 \mathrm{~cm}$ diameter, $20 \mathrm{~cm}$ length). Each cylinder was connected to a burette $(50 \mathrm{~mL}$ by a flexible tube (Fig. 1). Cylinder and burette were clamped next to each other on a board and protected from light. Aeration rate was low and the relative humidity of the pressurized air was increased by leading it through a washing bottle to reduce evaporation from the solution to about $1 \mathrm{~mL} / \mathrm{d}$.

Daily, the level in the cylinders was adjusted to a mark by raising the burette (accuracy of adjustment was 0.1 to $0.5 \mathrm{~mL}$ ). Evapotranspiration was read from the burette. Evaporation (as estimated from 3 blane cylinders) was compensated for by adding water. After lowering the burette, a volume of nutrient solution was added into the cylinder, equal to the transpired volume.

The experiment was carried out in a fytotron. Growth conditions were: light period $13 \mathrm{~h}$; light intensity $120 \mathrm{~W} / \mathrm{m}^{2}$ at plant height; day/night temperature $27 / 20^{\circ} \mathrm{C} ; 80 / 80 \%$ relative humidity.

\section{Nutrient solutions}

At the start the cylinders were filled with a nitrogen free initial solution containing (in $\mathrm{m} M$ ): $5.2 \mathrm{~K} ; 0.4 \mathrm{Ca} ; 0.4 \mathrm{Mg} ; 2.6 \mathrm{H}_{2} \mathrm{PO}_{4} ; 1.3 \mathrm{SO}_{4} ; 1.6$ Cl. Trace element concentrations were (in $\mathrm{mg} \mathrm{L}^{-1}$ ): $4.6 \mathrm{Fe} ; 0.5 \mathrm{~B} ; 0.5 \mathrm{Mn} ; 0.05 \mathrm{Zn} ; 0.02$ $\mathrm{Cu} ; 0.01 \mathrm{Mo}$. $\mathrm{Fe}$ was added as a mixture of Fe-sulphate and citric acid.

Four treatments (replicated 3 times) were used, receiving $10,20,30$ and $40 \mathrm{mmol} \mathrm{N}$ per litre transpiration $(\mathrm{CN})$ respectively. Nitrogen 


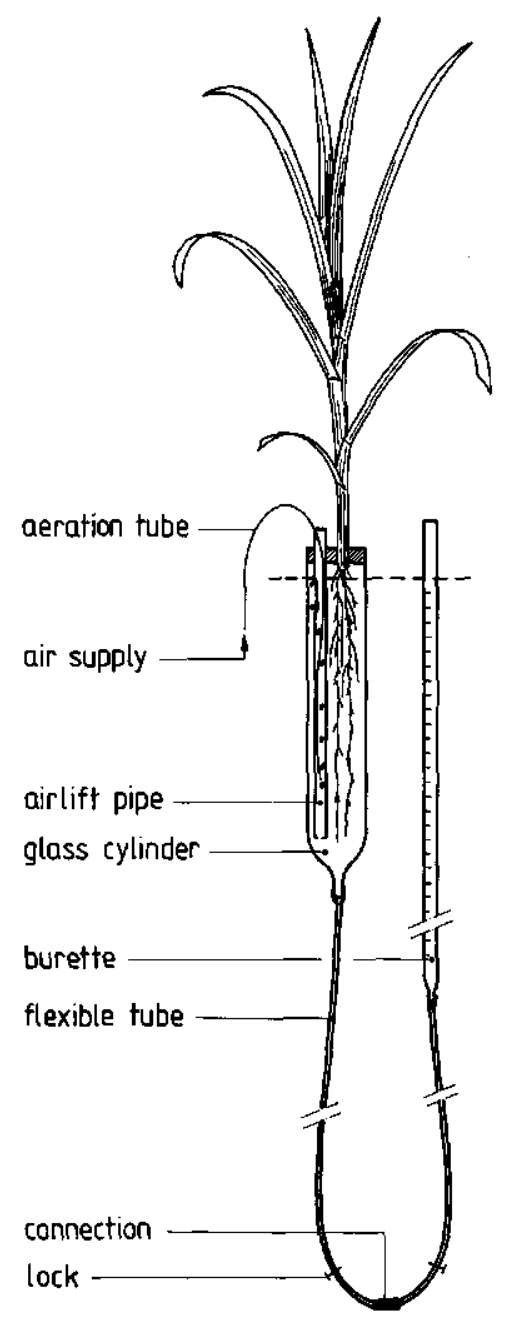

Fig. 1. Schematic representation of the communicating vessel system used for short term experiments with transpiration controlled nutrient supply. (Further explanation in text.)

was added with complete nutrient solutions. Macro-nutrient concentrations in the first treatment solution $(\mathrm{CN}=10$ ) were $($ in $\mathrm{m} M): 5.0 \mathrm{~K}$; $0.3 \mathrm{Ca} ; 0.3 \mathrm{Mg} ; 2.8 \mathrm{NH}_{4} ; 7.2 \mathrm{NO}_{3} ; 0.6 \mathrm{H}_{2} \mathrm{PO}_{4}$; $0.3 \mathrm{SO}_{4} ; 0.6 \mathrm{Cl}$. Trace element concentrations in this solution were one tenth of those in the initial solution. Concentrations in the other treatment solutions were respectively 2,3 and 4 times as high. The macro-nutrient composition of these solutions was in accordance with earlier determined uptake ratios of Pennisetum plants. The $\mathrm{NH}_{4} / \mathrm{NO}_{3}$ ratio was adjusted to balance the cation/anion uptake ratio and minimize plantinduced $\mathrm{pH}$ changes in the initial solution.

\section{Observations}

Transpiration of each plant was measured daily. On 12, 14, 17, 21, 24 and 27 DAS the following observations were made: fresh weight of the plant including water adhering to the roots after a standard dripping time (FWPLwet), root volume, number of young, mature and dead leaves, length and width of each leaf, tiller number, length of the main stem. Solution $\mathrm{pH}$ and $\mathrm{NO}_{3}$ and $\mathrm{NH}_{4}$ concentration in the cylinder were measured also. These non-destructive observations allow estimation of RGR, ANPL and NCPL (based on wet fresh weight). RGR and nitrogen productivity (NP) were calculated using the following equation:

$$
\mathrm{RGR}, \mathrm{NP}=\mathrm{GR} /[(\mathrm{X} 2-\mathrm{X} 1) / \ln (\mathrm{X} 2 / \mathrm{X} 1)]
$$

where GR is the absolute growth rate ( $\mathrm{g} /$ plant / d) and $\mathrm{X} 1$ and $\mathrm{X} 2$ are the values of FWPLwet resp. ANPL at the start (X1) and the end (X2) of the time interval.

On 27 DAS the plants were harvested. Leaf area, fresh and dry weight of the roots, stems and leaves were determined. Whole plants were analyzed for $\mathrm{NO}_{3}$, total $\mathrm{N}, \mathrm{P}$ and $\mathrm{K}$ (methods according to Novozamsky et al., 1983a; b).

\section{Results}

Only results relevant for the evaluation of transpiration controlled nutrient supply are shown in this paper. Most graphs and calculations are based on FWPLwet. When relevant, values based on estimates of fresh weights without adhering water (FWPL) and dry weights (DWPL) are given in the text.

Analysis of the nitrogen concentration in the cylinders indicated complete uptake of the nitrogen added within 24 hours in all four treatments. Therefore, the course of the NCPL (based on fresh weights) can be estimated from initial ANPL, the cumulative $\mathrm{N}$-additions and FWLPwet. Final NCPL estimated in this way on 27 DAS ( $\mathrm{NCPL}_{\text {est }}$ ) correlated well with the results of the chemical analysis (NCPL $\mathrm{N}_{\text {meas }}$ ), but there was a small systematic deviation 
$\left(\mathrm{NCPL}_{\text {est }}=\mathrm{NCPL}_{\text {meas }} \times 1.15-128 ; \mathrm{r}^{2}=0.974\right)$. Final plant weights differed a factor five $(0.89$, $1.81,2.74$ and $4.42 \mathrm{gDW} /$ plant at $\mathrm{CN}=10,20$, 30 and $40 \mathrm{~m} M$ respectively).

Adaptation of NCPL and RGR to the treatment took about 5 days at the highest $\mathrm{N}$-level and 9 days at the lowest $\mathrm{N}$-level (Fig. 2). Thereafter, changes in NCPL were relatively small (mean coefficient of variance (CV) between harvests was $14 \%$; mean $\mathrm{CV}$ between replicates was $6 \%$ ), whereas RGR showed a substantial and steady decrease after the adaptation phase (decrease during the last week with $50 \%$ at the highest $\mathrm{N}$-level and $75 \%$ at the lowest $\mathrm{N}$-level; mean $\mathrm{CV}$ between replicates was $8 \%$ ).

Final NCPL was highly correlated with the $\mathrm{N}$-concentration in the nutrient solution (Fig. 3),
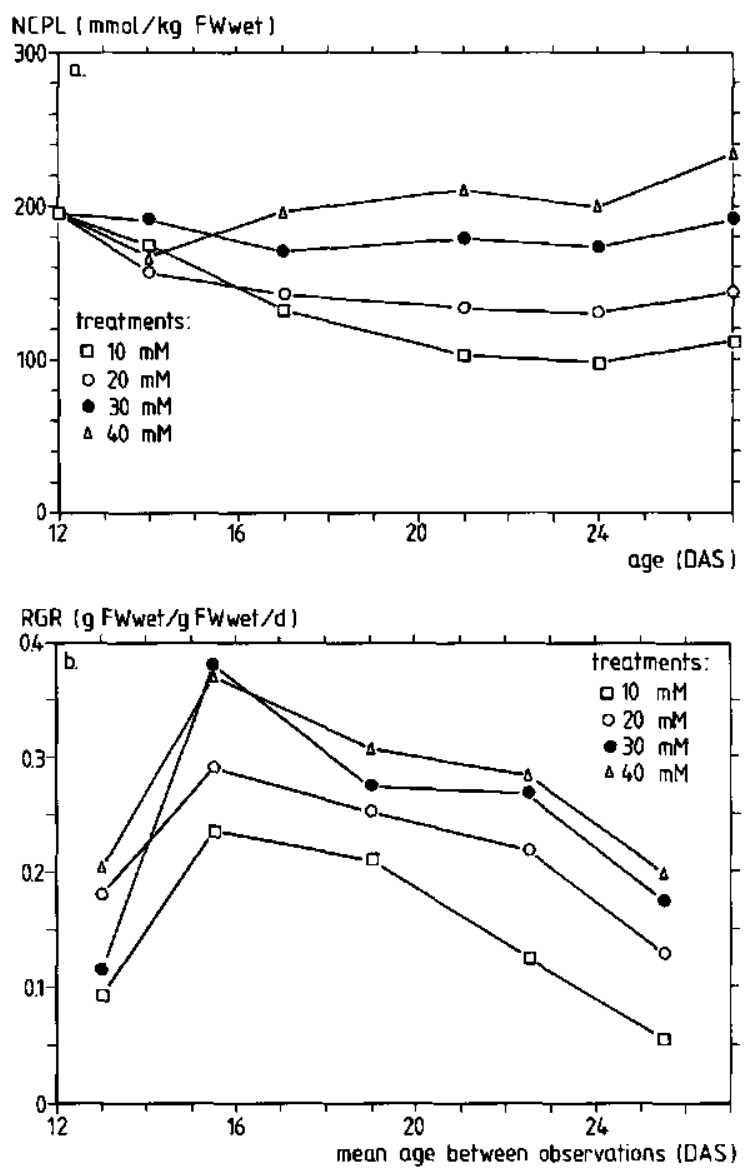

Fig. 2. Course of the plant N-concentration (NCPL; a) and relative growth rate (RGR; b) of Pennisetum americanum with age. Means of three replicates are shown. Four N-levels were induced using transpiration controlled nutrient supply with $10,20,30$ and $40 \mathrm{mmol} \mathrm{N}$ per litre transpiration.

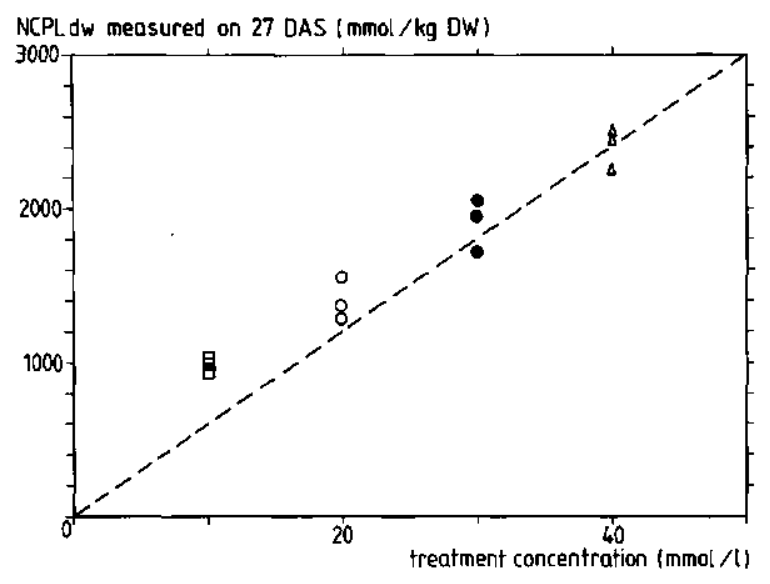

Fig. 3. Relation between final plant $\mathrm{N}$-concentration of Pennisetum Americanum (NCPLdw) and treatment N-concentration (mmol/L transpiration) appljed in transpiration controlled nutrient supply. The straight line through the origin represents the relation expected from Equation 2 when TC is constant $(60 \mathrm{~L} / \mathrm{kg} \mathrm{DW})$.

but the relation does not pass through the origin, contrary to expectation if TC would be constant and independent of nutrient status (see Equation 2 ). Figure 4a shows that TC decreased slightly in time in the three highest $\mathrm{N}$-levels (less than $10 \%$ in ten days). However, at the lowest $\mathrm{N}$-level TC increased considerably (almost 100\%) towards the end of the experiment.

To relate TC, RGR and NP to the nutrient status of the plant the mean NCPL between 24 and 27 DAS was calculated from the mean FWPLwet and the mean ANPL during the interval. The latter means were calculated using the last term in Equation 3.

Figure $4 \mathrm{~b}$ shows that $\mathrm{TC}$ was hardly influenced by the substantial $\mathrm{N}$-stress at $\mathrm{CN}=20 \mathrm{mM}$, where the final yield was only $40 \%$ of the final yield at $\mathrm{CN}=40 \mathrm{~m} M$ and NCPL was about 140 $\mathrm{mmol} / \mathrm{kg}$ FWwet $(170 \mathrm{mmol} / \mathrm{kg}$ FW or 1760 $\mathrm{mmol} / \mathrm{kg} \mathrm{DW}$ ). This affirms the conclusion of De Wit (1958) and Tanner and Sinclair (1983) that transpiration efficiency changes little, if at all, until nutrient deficiency reduces yield to about half that on well-fertilised soil. TC increased sharply at $\mathrm{CN}=10 \mathrm{mM}$, where the final yield was reduced to $20 \%$ of the highest $\mathrm{N}$-level and NCPL dropped to $100 \mathrm{mmol} / \mathrm{kg}$ FWwet (about $120 \mathrm{mmol} / \mathrm{kg} \mathrm{FW}$ or $1000 \mathrm{mmol} / \mathrm{kg} \mathrm{DW}$ ).

TC is about $6 \mathrm{~L} / \mathrm{kg}$ FWwet $(6.5 \mathrm{~L} / \mathrm{kg} \mathrm{FW} ; 65$ $\mathrm{L} / \mathrm{kg} \mathrm{DW}$ ) at the two highest $\mathrm{N}$-levels. This is 

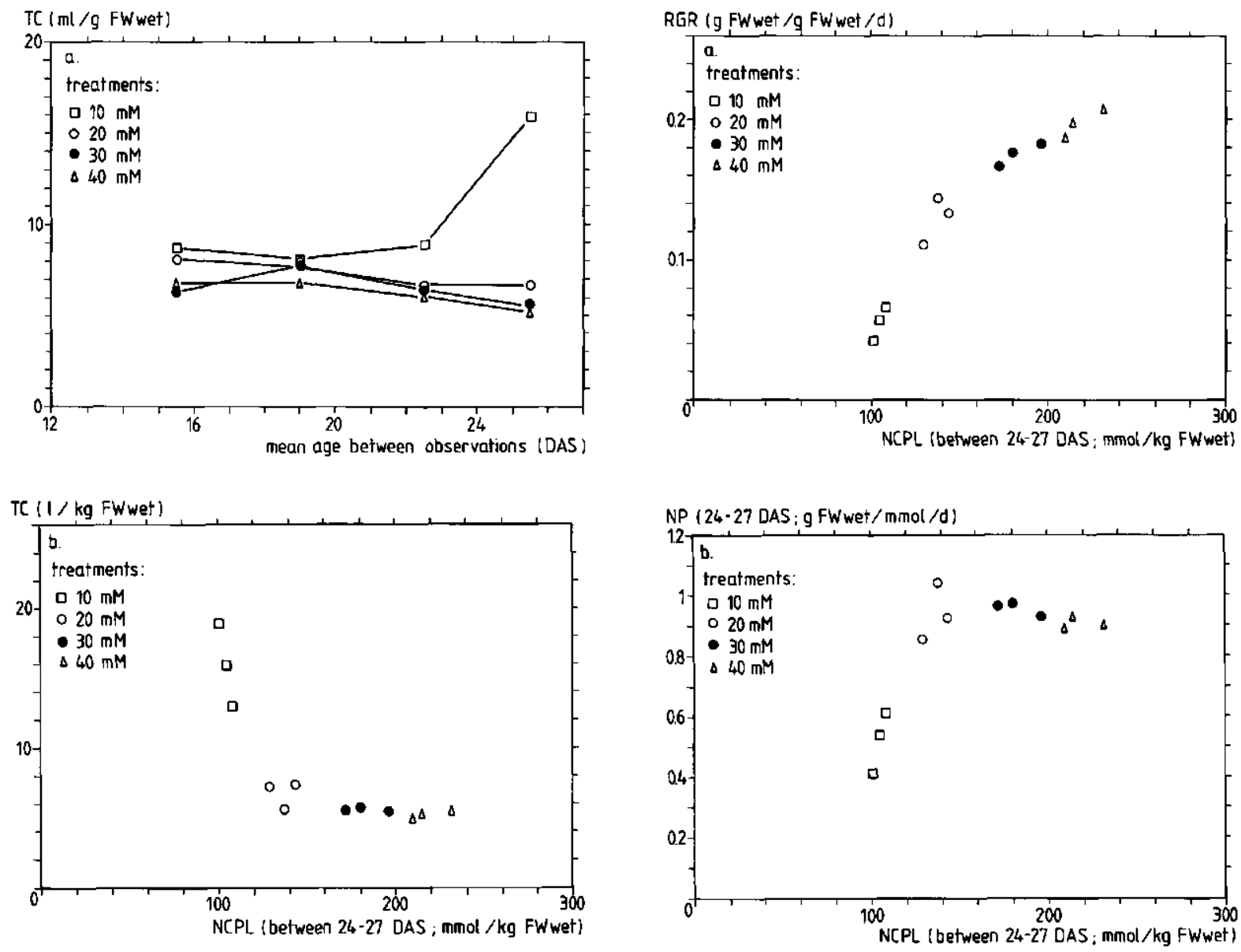

Fig. 4. Transpiration coefficient (TC) of Pennisetum americanum plotted against age (means of three replicates are plotted between the observations dates (DAS); a) and against plant N-concentration (NCPL; TC of individual plants is plotted against mean NCPL between 24 and 27 DAS; b).

low compared to values commonly found in literature, because $\mathrm{TC}$ is expressed on a whole plant basis, millet is a $\mathrm{C} 4$ species, and the evaporative demand in the climate room was low.

RGR depends strongly on NCPL (Fig. 5a). The relation is not linear, as is often found (Ingestad and Lund, 1986), nor does it resemble the relation found by Hirose (1988) and Hirose et al. 1988). However, when NCPL is calculated for organic $\mathrm{N}$ instead of total $\mathrm{N}$ (not shown), a curvilinear relation is found, resembling the curve presented by Hirose (1988). Below

Fig. 5. Relation between relative growth rate (RGR; a) and nitrogen productivity (NP; b) with plant $\mathrm{N}$-concentration (NCPL; RGR of individual plants is plotted against the mean NCPL between 24 and 27 DAS).

$140 \mathrm{mmol} / \mathrm{kg}$ FWwet RGR bends down. By extrapolation the minimum NCPL is found to be about $90 \mathrm{mmol} / \mathrm{kg}$ FWwet. The N-productivity (NP) reaches its optimum at $\mathrm{CN}=20 \mathrm{~m} M$ (NC $\mathrm{PL}=$ about $140 \mathrm{mmol} / \mathrm{kg}$ FWwet; Fig. 5b). A similar curve was found by Hirose (1988) and Hirose et al. (1988).

\section{Discussion}

The fact that NCPL was almost constant after 
the adaptation phase while RGR decreased considerably, indicates that transpiration controlled $\mathrm{N}$-supply suitably maintained steady state nutrition in these non-exponentially growing plants. It can be inferred from Figures $2 a$ and $2 b$, that use of a constant RAR of $0.2 \mathrm{~d}^{-1}$ would have shifted the $\mathrm{N}$-level in the plants from lower than the lowest to about the highest $\mathrm{N}$-level used in this experiment. This would have resulted in a twofold increase in NCPL, which would almost have eliminated the nutritional control of growth.

To maintain a really constant plant $\mathrm{N}$-concentration with transpiration controlled nutrient supply, TC should be constant with time. At the three higher $\mathrm{N}$-levels $\mathrm{TC}$ was almost constant. It should be tested for longer growth periods whether the slight decrease is significant. The increase in $\mathrm{TC}$ at the lowest $\mathrm{N}$-level has resulted in improved $\mathrm{N}$-supply during the last days of the experiment. This has prevented NCPL from decreasing below $100 \mathrm{mmol} / \mathrm{kg}$ FWwet.

Final NCPL on 27 DAS was proportional to the solution $\mathrm{N}$-concentration $(\mathrm{CN})$ only for the three higher N-levels (Fig. 3). At the lowest $\mathrm{CN}$ the proportionality disappeared as a consequence of the increase in TC during the last days of the experiment.

It is concluded that transpiration controlled nutrient supply allows control of plant $\mathrm{N}$-concentrations, except at the lowest $\mathrm{N}$-levels. When the actual TC is known $\mathrm{CN}$ can be adjusted to give any desired plant $\mathrm{N}$-concentration. This possibility may be interesting for research purposes, as well as for commercial greenhouse crop growing.

The communicating vessel technique used for transpiration controlled nutrient supply is basically simple, though it requires more time per plant and accuracy of handling than other possible techniques, using transpiration measurements by weighing the pots. This was compensated by using non-destructive observations instead of sequential harvesting, which allowed a considerable reduction in the number of plants. Correction for the increase in root volume is not considered necessary, because it causes only a small systematic error of about $3 \%$ of the volume transpired.
RGR and NP fitted remarkably smooth to NCPL, even though individual plants were plotted in Figure 5. The position of the points from replicate plants indicates that variations in $R G R$ and NCPL are positively correlated. Probably these variations are due to spatial variability in transpiration rate within the climate room, causing differences in nutrient supply rate, but not affecting TC and the relation between RGR and NCPL. Coefficients of variance between replicates in NCPL, RGR and TC were low, decreasing in the adaptation phase to $6 \%, 8 \%$ and $8 \%$ respectively. The coefficient of variance in FWPL was however maintained at the initial value of $14 \%$. As in the PNA technique this variance could be reduced by supplying replicate plants with equal amounts of nutrient solution (using mean transpiration rates, instead of individual transpiration rates).

The technique resembles a sand culture where nutrients are supplied by watering with nutrient solution, but it allows a more direct and accurate control over nutrient uptake. There is no store in the root medium, because uptake is instantaneous and complete. As with Programmed Nutient Addition, the size of the root system can in no way influence the nutrient uptake of the plant. Consequently, efforts of the plant to compensate for the lack of nutrients (by increasing biomass investments in roots) cannot reduce the differences in nutrient supply between experimental treatments, as may happen with other culture techniques. This is an advantage in studying the effect of nutrient status on allocation and internal use efficiency of nutrients. On the other hand, the technique cannot be used in studying the 'reward' for the increased biomass investment in roots in terms of uptake and growth.

\section{Acknowledgements}

The authors thank Friederike de Mol and Vincent Deenen for carrying out the experiments with great diligence and accuracy. We thank $G R$ Findenegg, E Hoffland, $\mathrm{H}$ van Keulen and $\mathrm{B}$ W Veen for helpful discussions during experimentation and preparation of the manuscript. 


\section{References}

De Wit C T 1958 Transpiration and crop yields. Agric. Res. Rep. 64.6. Pudoc, Wageningen, 88 p.

Hirose T 1988 Modelling the relative growth rate as a function of plant nitrogen concentration. Physiol. Plant. $72,185-189$.

Hirose T, Freijsen A H J and Lambers $\mathrm{H} 1988$ Modelling of the responses to nitrogen availability of two Plantago species grown at a range of exponential nutrient addition rates. Plant Cell Environ. 11, 827-834.

Ingestad T and Lund A-B 1986 Theory and techniques for steady state mineral nutrition and growth of plants. Scand. J. For. Res. 1, 439-453.

Novozamsky I, Houba V J G, Van Eck R and Van Vark W 1983a A novel digestion technique for multi-element plant analysis. Commun. Soil Sci. Plant Anal. 14, 239-249.

Novozamsky I, Houba V J G, Van der Eyk D and Van Eck R $1983 \mathrm{~b}$ Notes on determination of nitrate in plant material. Neth. J. Agric. Sci. 31, 239-248.

Schapendonk A H C M, Spitters C J T and De Vos A L F 1990 Comparison of nitrogen utilization of diploid and tetraploid perennial ryegrass genotypes using a hydroponic system. In Genetic Aspects of Plant Mineral Nutrition. Eds N El Bassam, M Dambroth and B C Loughman. pp 299-306. Kluwer Academic Publishers, Dordrecht, The Netherlands.

Tanner C B and Sinclair T R 1983 Efficient water use in crop production: research or re-search? In Limitations to Effcient Water Use in Crop Production. Eds. H M Taylor, W $R$ Jordan and T R Sinclair. pp 1-27. ASA Monographs Inc., Madison, WI.

Van Keulen H and Seligman N G 1987 Simulation of Water Use, Nitrogen Nutrition and Growth of a Spring Wheat Crop. Simulation Monographs. Pudoc, Wageningen, $310 \mathrm{p}$.

Van Koninckxloo M 1986 Application of the nitrogen productivity concept to the fertilisation of maize. Agro 5, 13-28.

\section{Appendix}

Abbreviations:

ANPL: total amount of $\mathrm{N}$ in plant + pot (mmol/plant);

$\mathrm{CN}$ : concentration of $\mathrm{N}$ in the nutrient solution $(\mathrm{mmol} / \mathrm{L})$;

CV: $\quad$ coefficient of variance (\%);

DAS: days after sowing;

DWPL: plant dry weight (g DW/plant);

FWPL: $\quad$ lant fresh weight (g FW/plant);

FWPLwet: FWPL including water adhering to the roots (g FWwet/plant);

GR: $\quad$ growth rate; $G R=\left(\right.$ FWPLwet $_{2}-$ FWPLwet $\left.{ }_{1}\right) /\left(t_{2}-t_{1}\right)$

$\mathrm{N}$ : the growth limiting nutrient being nitrogen in the present experiment;

NCPL: internal plant $\mathrm{N}$-concentration (mmol/kg);

NP: $\quad$ N productivity $(\mathrm{g} / \mathrm{mmol} / \mathrm{d})$;

PNA: technique of programmed nutrient addition;

RAR: relative addition rate $(1 / \mathrm{d}) ; \mathrm{RAR}=$ d(ANPL)/(dt.ANPL)

RGR: relative growth rate $(1 / \mathrm{d})$;

SSN: the condition of steady state nutrition;

$\mathrm{t}$ : time in DAS;

TC: transpiration coefficient $(\mathrm{L} / \mathrm{kg}$ increment). 